\title{
The view from Northern Ireland - BDJ meets Tristen Kelso
}

\author{
Interview by David Westgarth
}

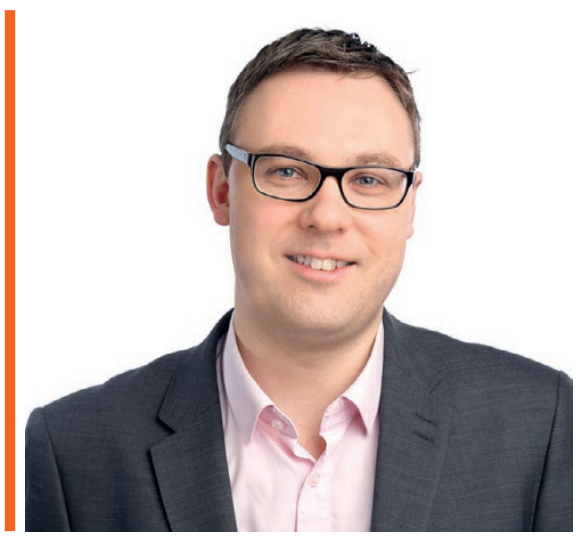

\section{How have you found your role given the unique situation and resulting challenges you face?}

Coming from a policy background and having supported a wide range of organisations achieve their objectives through navigating the world of politics, the first task has been familiarising myself with the big issues within dentistry and among dentists. What I've found is a profession under real pressure. GDPs have seen their earnings fall by between a quarter and a third in real terms over the past seven years while expenses have soared. Levels of morale among Northern Ireland dentists is the lowest anywhere in the UK, and at the same time, the regulatory burden has continued to increase.

A key objective I have is to have dentistry and dental professionals elevated in terms of government priorities within the Department of Health, and across all government Departments. I believe there are opportunities to do just that, but we need to show relevance to the pressing issues, and we need to reach out to a wider external audience.

While we have no Executive in place currently, BDA Northern Ireland has been engaging extensively at official level; for example, with the Department of Health and the Health and Social Care Board. In our contacts at Chief Dental Officer (CDO) and Permanent Secretary level, we have

\author{
On 4 September 2017, Tristen Kelso was appointed Director, BDA Northern \\ Ireland, against a backdrop of political uncertainty in the country. A year later \\ there is still no sign of Northern Ireland Assembly in Stormont, so how has \\ he spent the time in office? BDJ In Practice and BDJ Student Editor David \\ Westgarth met with Tristen to find out.
}

highlighted the gaps in oral health - including the unacceptably high GA extraction rate for children - and the gaps in provision for our older population. We've challenged the Department to stop treating dentistry in isolation and to have a bigger vision of the wider public health benefits that could be delivered with a greater focus on and additional resources into oral health and the profession.

However, rather than focusing on what is out of our control, we've used this time to establish relationships with most of the health spokespersons of the political parties, and to brief them on our issues.

Finally, we are now two years after our community dental services (CDS) members were balloted on their new contract, and still this has yet to be implemented. The absence of Executive Ministers has certainly not helped in this delay, particularly when decision making appears to have fallen to risk-averse accountants.

You've mentioned income. How badly are members in Northern Ireland - and indeed the entire workforce - being affected by the financial squeeze on health service dentistry?

Austerity, with a reduced pot of money for health, combined with the rising demand on the NHS and the rate of inflation in providing healthcare, on top of the imposition of a $1 \%$ pay cap has created extremely difficult conditions for everyone dependent on the NHS for their livelihood. The impact on dentists has been made even greater, as they have had to absorb these rising costs out of their own pockets. The ability to invest in dental practices has been severely hampered.

While the $£ 1$ million Revenue Grant Scheme was a much-needed boost this year, we need to see future initiatives aimed at ensuring the future sustainability and viability of dental practices going forward.

We're also mindful that associates have seen their average earnings fall by approximately a third in the past seven years, and they are among the lowest paid in the whole of the UK.

\section{Has the rise of the corporates driven or influenced this?}

The impact of corporates on the working conditions of our dentists is being looked at very carefully by the BDA. An increase in their presence in the market is certainly a reality. Perhaps the wider economic conditions have made it more difficult for individual associates to follow what was the traditional pattern of buying into a practice, and corporates have filled the gap.

The squeeze on earnings has been primarily down to cuts on public 
1 spending, and the expectation that providers will 'take the hit'. This simply isn't sustainable any longer, and I think the message is starting to get through to government that the NHS can no longer be run on a shoestring - hence the extra $£ 20$ billion 70th anniversary present. If, according to the economic experts, the health service requires $4 \%$ plus inflation each year simply to address rising costs, as far as we are concerned, dentistry is no different.

\section{Without a government in place in Northern Ireland I guess it's hard to tangibly do something about that?}

Depending on what area practices are located, dentists to varying extents are keeping a close eye on their private vs NHS mix. NHS Digital Earnings figures show that dentists start to lose out financially once they exceed over $75 \%$ health service dentistry, and stress levels go up also. The real game-changer will be when government needs dentists more than dentists need government.

Despite not having a government, we've been deliberately ramping up the BDA's visibility and seeking to sharpen our core messages. The same needs remain, and our officials are in no doubt as to what our expectations are if and when the Assembly does return. It would obviously be a real help if we had a supportive Health Minister or Chair of the Health Committee in place who appreciated the importance of oral health, and made the necessary investment in it that is so badly needed.

You're more than 500 days without a government in Northern Ireland (NI). Has that time allowed you to work behind the scenes to formulate a new oral health strategy that you can campaign for when a government is formed?

That's the approach we have tried to adopt, with a varying degree of success. Jim Shannon MP has been supportive towards us and highlighted our messages on child oral health outcomes in a Westminster Hall debate. He usefully wrote to the Permanent Secretary early this year to press him on the need for a new oral health strategy, and made the case that oral health should be regarded as a higher priority. A 10-page response was received from Richard Pengelly, which regrettably was primarily concerned with justifying the status quo rather than looking at ways of making meaningful improvements, such as working towards a new strategy.

The Chairs of our three BDA NI committees had an opportunity to meet with our CDO on the issue of child oral health outcomes, and to make the case for a new oral health strategy. We recognise this is still a work in progress, but we believe we are making some headway in encouraging officials to be more strategic in how they view dentistry when they are bidding for additional funding.

\section{What plans are afoot to improve these figures? Scotland and Wales are known for their innovative schemes, and although it is limited in funding England also has one too. What can we expect from NI?}

Unlike Childsmile in Scotland and Designed to Smile in Wales, Northern Ireland doesn't have a comparable scheme, but rather there are various local activities taking place. Our Department of Health points to the significant oral health improvements that have been
What challenges are you anticipating in the future?

There are various dental workforce issues already becoming apparent, not least a shortage of dental nurses. Our CDS is under enormous pressure in terms of capacity, and there could be a high proportion of retirements in the not-so-distant future. There appear to be real gaps in provision for our older population. While some work is being done around a number of these issues, we need to be dealing with these issues in a co-ordinated way.

\section{Is there enough focus on the oral health needs of the elderly? So much time and money - and rightly so - is invested in children, but the elderly have significant complexities to deal with.}

It certainly shouldn't be a case of 'either or', and actually I've been struck by the focus on preventive dentistry for both cohorts. While the health and wellbeing of older people is a huge issue, their oral health and provision

\section{'I think the message is starting to get through to government that the NHS can no longer be run on a shoestring...'}

made over various child oral health surveys. However, we have over 5,100 child general anesthetic (GA) extractions per year, a rate which is three times higher (pro rata) than in England.

We need to be looking closely at what works and applying the best of this learning locally. Regrettably, to date we haven't been met with any real ambition or contagious enthusiasm at official level towards exploring any new initiatives. This is why our calls for a new oral health strategy is less about the document itself and more about injecting fresh ambition, energy and commitment into dentistry and its contribution to improving population oral health, wider health and wellbeing. We also need a suitable vehicle to help drive this strategic piece of work forward, to be comprised of a number of key stakeholders, including the Department and theBDA. We have suggested a re-worked Northern Ireland Oral Health Improvement Group could perhaps take this forward. hasn't been something that has had much attention. In recent months, we've met with the Chief Executive of Age Sector Platform to discuss oral health issues. In the past month, we had an excellent meeting with Eddie Lynch, Commissioner for Older People for Northern Ireland. Eddie is a breath of fresh air, and his recent investigation into Dunmurry Manor demonstrates what an older person's champion looks like. Eddie is very supportive of working with us to press for improved oral health provision for older people.

\section{How much of this is linked to the lack of a CDS contract?}

The CDS is underfunded and massively overstretched, and they're doing a heroic job in the circumstances. However, the way in which they've been let down in having their terms and conditions updated has been appalling, and has had a negative impact on morale. There are also wider capacity issues within the care homes themselves. 
It goes back to the oral health strategy, and lack of it. That strategy should seek to have a vision for improved oral care for older people as well as for the youngest in our society. Unfortunately, it appears to take a crisis of some sort to force our authorities to take notice and make changes. Perhaps the Dunmurry Manor episode can lead to something positive.

\section{What opportunities are there for dentistry in NI?}

There is an opportunity to create a culture shift whereby dentists and their representatives in the BDA need to be included in the design and commissioning of dental services, through greater co-production.

There could be more imaginative thinking to commission general dental services to be involved in delivering more prevention/care for the elderly, taking some of the pressure off the CDS and being adequately remunerated in return. If we get oral health and dentistry up the agenda, suddenly, we are relevant to the wider prevention and transformation agendas, and our issues become important to the future of health and social care. The logic to this is that the resources should follow where wider health and wellbeing of the population can be delivered. used this to generate quite a lot of media coverage, and highlight the growing problem that is oral cancer.

One of the practical steps government could do is to extend the HPV vaccine to

\section{'Unfortunately, it appears to take a crisis of some sort to force our authorities to take notice and make changes...'}

\author{
How are you hoping to tackle the \\ growing problem that is oral cancer? \\ We have established a really positive working \\ relationship with Cancer Focus NI, the \\ leading cancer charity in Northern Ireland. \\ Last November, we rolled out a \#mouth- \\ checkni initiative, where dentists carried \\ out oral cancer checks in West Belfast on \\ purpose built Cancer Focus NI vans. We
}

\begin{abstract}
boys. BDA NI issued a joint press release on this topic with Cancer Focus NI following the positive announcements elsewhere; we also wrote to the DH Permanent Secretary, and to all the political party health spokespersons. A reply from the Permanent Secretary assured us that all preparatory work is being taken forward short of ministerial sign-off, which will require a minister to be in post.
\end{abstract}

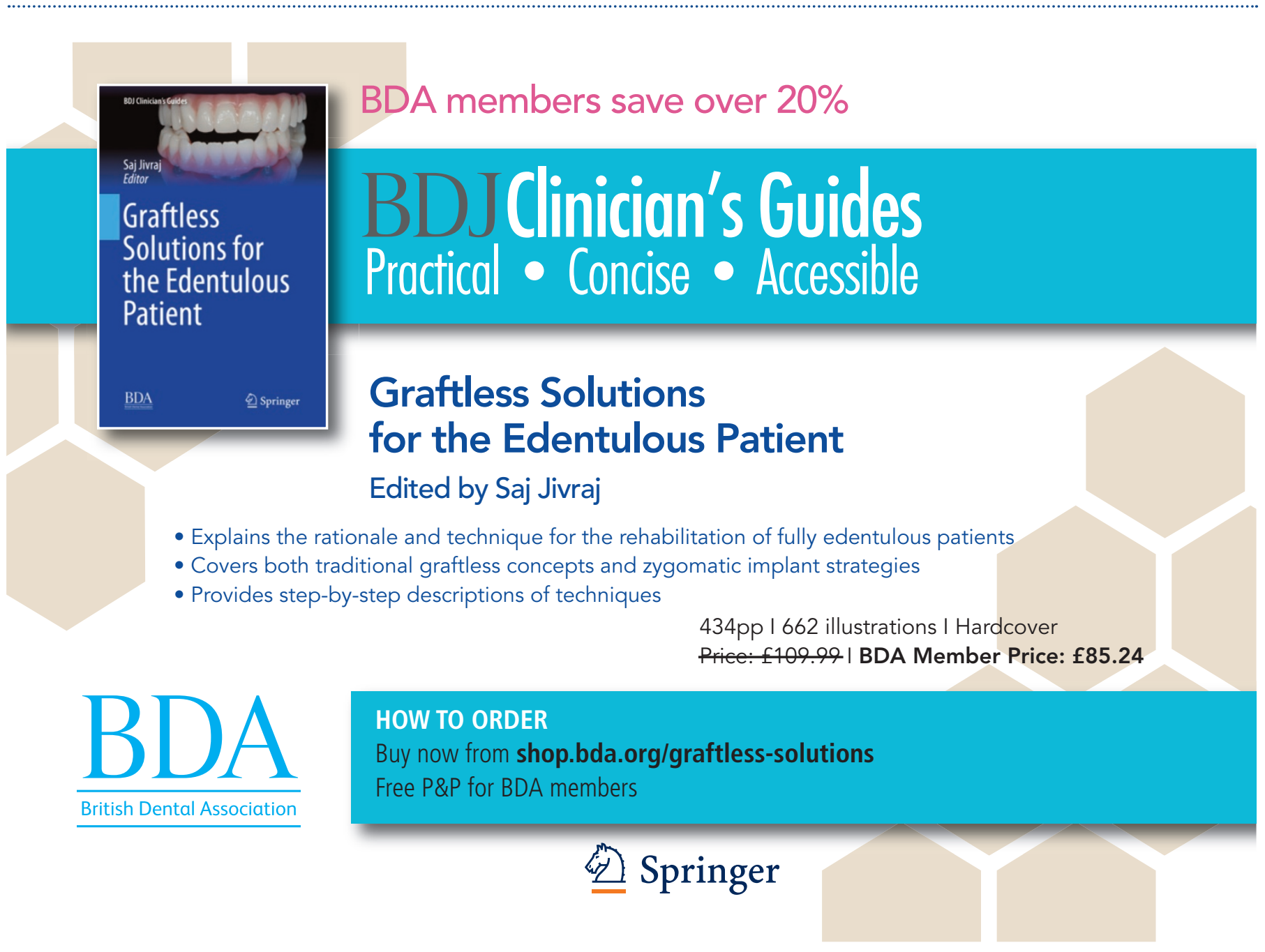

